\title{
Successful new product development in the food packaging industry: evidence from a case study
}

\author{
Barbara Bigliardi, Eleonora Bottani, Roberto Montanari \& Giuseppe Vignali
}

Department of Industrial Engineering, University of Parma, Viale G.P.Usberti 181/A - 43124 Parma, ITALY

*Corresponding Author: Giuseppe Vignali, giuseppe.vignali@unipr.it; Tel. +39 0521 906061; Fax +390521905705

\begin{abstract}
The relevance of product innovations and new product development for the competitive performance of firms and for the longterm economic growth is a known and recognized topic. In the context of the food industry, process and product innovations are usually the result of cross-discipline ideas, involving, for instance, biology, chemistry, technology, engineering, nutrition and law. Furthermore, the food industry suffers from the fact that the benefits of innovations are often not evident at the manufacturing stage. This paper analyzes a successful case of product innovation, in the context of the Italian food industry. The analysis is proposed in the form of a case study-based research, which was carried out through a questionnaire survey and some field interviews with managers of a food company located in Northern Italy. Specifically, the company selected operates as a packaging manufacturer, providing plants, equipments and sachets for food and drink packaging. The study focuses on the development of a new product, which the company has recently launched on the market in response to the needs of packaging liquid, viscous or creamy foods. By presenting a successful case study, this paper aims to highlight the strengths and weaknesses of the new product development process undertaken by the company (i.e., from the idea of the new product to the launch on the market and patent). At the same time, results presented provide useful guidelines for new product development processes in the food context.
\end{abstract}

Keywords: product innovation, new product development, patent, food packaging industry, case study.

\section{Introduction}

Innovation is widely recognized, from both academics and managers, as a fundamental requisite of a company in order to grow in today's competitive context, and as one of the key drivers of the firms' long-term success (Baker and Sinkula, 2002; Balkin et al., 2000; Darroch and McNaugton, 2002; Lyon and Ferrier, 2002). The reason is that innovative companies will be able to respond to environmental challenges faster and better than the non-innovative ones (Jimenez et al., 2008). Therefore, organizations have been forced to embrace innovation as an integral part of their corporate strategy, and to offer products that are adapted to the needs of target customers in order to create a sustainable competitive advantage and to stay ahead of the competition (Calantone et al., 1995; Damanpour and Gopalakrishnan, 2001; Scarborough and Zimmerer, 2002). During the last decades, a shift has been observed from the technology push innovation model to the market pull one, thus forcing companies to focus more on quality product rather than on internal efficiency, and to quickly identify changing customers' needs, to develop more complex products to satisfy those needs, and to provide higher level of customer supports and service (Sheperd and Ahmed, 2000). As a consequence, greater focus has been placed on new product development (NPD).

Taking account of the above, this paper examines an example of successful NPD process. The literature review reported in section 2 focuses on NPD, and discusses in particular the factors that may determine its success. In the same section, a brief mention to the protection of the results of NPD process is reported. Section 3 describes the research methodology followed for the study, while section 4 reports the results from the case study, that is the position of a small company operating in the food packaging industry. Specifically, the context investigated and the company are briefly described, followed by the description of the new product developed, the related five-step NPD process and some economic figures. In conclusions, some guidelines are extrapolated from the case study, and managerial implications and future research directions are presented in section 5. 


\section{Literature analysis}

Innovation has been object of numerous studies in literature, notwithstanding, there is not a general definition of the term "innovation", thus generating greater ambiguity (Garcia and Calantone, 2002). However, innovation may be defined as the successful introduction of something new and useful, for example new methods, techniques, or practices or new or altered products and services. As for the different forms of innovation, Clarysse et al. (1998) and Lundvall (1992) identify four domains of innovation, interacting each other (Figure 1), namely:

1. Product innovation, that is any good, service or idea that is perceived by someone as new;

2. Process innovation, referring to the adaptation of existing production lines as well as the installation of an entirely new infrastructure and the implementation of new technologies, and generally it allows the creation of new products;

3. Organisational innovation, that is changes in marketing, purchases, sales, administration, management, staff policy and so on;

4. Market innovation, defined as the exploitation of new territorial markets and the penetration of new market segments within existing markets.

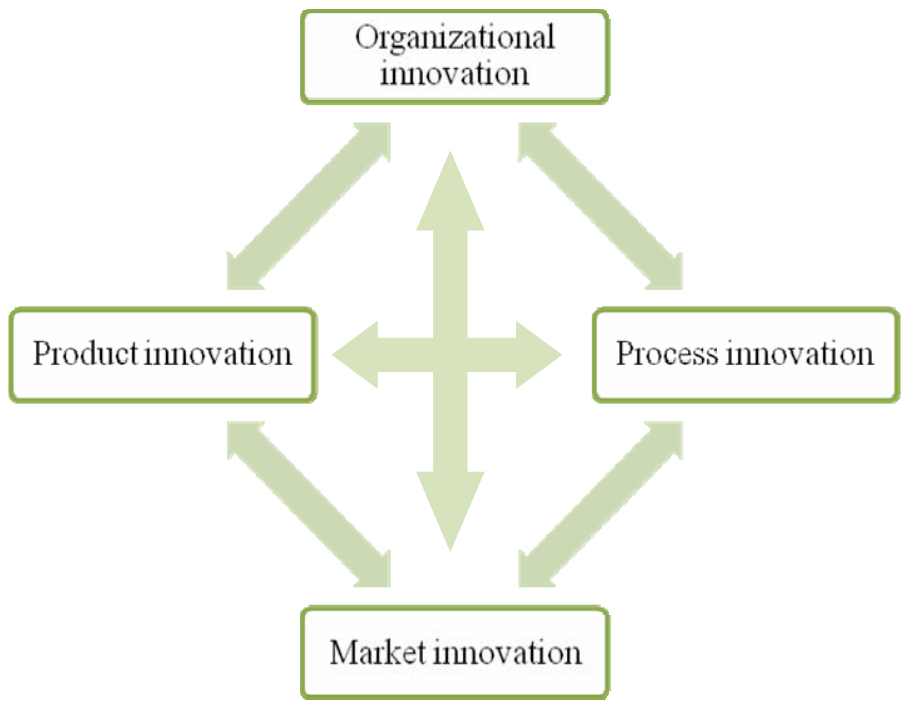

Figure 1. The four types of innovation.

The innovation process can be seen as a continuum starting from basic or applied research and ending with the development of a commercial product (IRI, 2000). Innovation projects, however, usually do not pass all the phases of this continuum, rather companies, depending on the type of project and the type of product/process to be developed, follow a specific path of innovation. NPD refers to the process of bringing a new product or service to market and involves several steps, namely idea generation, product design, product engineering, market research and marketing analysis, and so on. Companies typically see NPD as the first stage in generating and commercializing new products within the overall strategic process of product life cycle management. In today's environments, NPD is seen as a key factor mainly due to three reasons: first, the increasing international competition; second, the fragmenting and demanding markets; third the diverse and changing technologies (Wheelwright and Clark, 1992). Competitive advantage is more and more derived from knowledge, technological skills and experience in NPD (Tidd et al., 1997). Consequently, the NPD process has become the focus of recent research that may be classified into two main groups: (i) NPD process and (ii) NPD success.

Countless models, both normative and descriptive, have been proposed aiming at the definition of the steps to be followed to develop a new product. As for the normative models, it is possible to cite, for example, the works by Klompmaker et al. (1976) and Hanan (1970), which proposed a 27-steps model of NPD and a 24-activities flow diagram suitable for non-industrial goods respectively, while McGuire (1973) proposed a similar model for industrial goods. As far as the descriptive models are concerned, these have been developed on the basis of previous NPD projects or through direct observations of how firms manage a NPD project. What emerges from the study on this matter is that not all the steps are common to all NPD projects, nor are the steps necessarily undertaken with the same relative emphasis. However, most of these models agree in the identification of a series of phases, to be depicted schematically as a flow diagram, always present in the NPD process, regardless of the size of the company, the type of product or the industry it belongs to: a first "recognition phase", aiming at the exploration of new product needs, the "idea formulation and screening idea phase”, and, obviously, "the product development phase" (Cooper, 2001). 
In recent years, mainly due to the competitive environment where companies have to operate, another important phase is undertaken by more and more companies as the final phase of the NPD process: the protection of the new product, especially in the case of products that are strategic for the firm. Among all, the instrument widely recognized as the most effective one is the patent. Patents are generally accepted as indicators of the innovation and R\&D process, mainly due to the widespread availability of their statistics collected over long periods of time across nations and regions (Thomas et al., 2010). As stressed by Abraham and Moitra (2001), most studies have used patent statistics as a tool to investigate the relationship between technological development and economic growth, as well as to assess the research and innovation process within both a national and international context. Other studies have analyzed patents from an internal standpoint, thus assessing from a company's policy perspective the level of technology development in a specific industry, as well as analyzing a firm's policy with regard to R\&D, estimation of technological strengths and weaknesses of competitors, and exploitation of foreign markets (Abraham and Moitra, 2001). Thus, even though not all inventions are patented and not all patents are useful, they have become the most common indicator of innovative output. The economic literature also recognizes patents as the way to inhibit immediate direct competition and preserve an adequate profit margin (Malewicki and Sivakumar, 2004). Patents tend to cover product innovation (Drucker, 1985), as innovative products are supposed to be novel and non-obvious referred to previous knowledge as condition for issuance. Patenting activity may be undertaken both within the nation where the innovation is developed, and in a foreign country. As for the latter activities, these usually aim at protecting a potential market in that country for a firm's products, but due to the prolonged and expensive process usually required, companies often patent abroad only when it is confident that a relatively large market exists for its products in that specific country.

As for the NPD success matter, special attention has been paid to the measurement of innovation performance, and NPD performance in particular, and specifically to those factors that determine the success (or failure) of a NPD process. Success or failure of NPD activities have been found to be determined by the steps characterizing a NPD project as it moves from the idea generation to the new product commercialization (Rothwell et al., 1974). As there are different types of new products, the term successful NPD may be interpreted in many ways. Montoya-Weiss and Calantone (1994) for example, identified four categories of variables that determine the performance of a NPD process, and in turn, its success or failure, namely: (i) strategic factors, (ii) organizational factors, (iii) development process factors and (iv) market innovation factors. Cooper (1999) identified the eight factors listed below:

i. up-front homework before proceeding further from the idea stage;

ii. building in the voice of the customer;

iii. seeking differentiated and superior products;

iv. early and stable product definition before actual development;

v. strong market launch;

vi. tough go/kill decision points;

vii. organizing around cross-functional project teams;

viii. building an international orientation into the NPD process.

A research by Shepard and Ahmed (2000) reveals success factors within NPD process as follows:

i. a strong market orientation;

ii. an in-depth understanding of user needs and wants;

iii. a unique superior product, a product with a high performance to cost ratio;

iv. a strong market launch, backed by significant resources devoted to the selling/promotion effort;

v. an attractive market, a high need level, a large growing market, and uncompetitive market;

vi. synergy in a number of areas, including technological and marketing;

vii. top management support;

viii. good internal and external communications.

Shenar et al. (2002) proposed in their works three main dimensions of success: (i) meeting design goals, (ii) benefits to customers, and (iii) commercial success and future potential, while Millward and Lewis (2005), examining the performance of small and medium manufacturing firms, based their research on the consideration of the following factors affecting the success of the NPD process: (i) undertaking up-front research into competitors and suppliers, and building in the voice of the customer; (ii) sharp, early product definition in order to target differentiated, superior products; (iii) an international market-focused orientation with effective internal and external communications; (iv) competent, truly cross-functional project teams guided by strong project leaders; (v) senior management support with unhindered access to financial, personnel and political resources; (vi) thoroughly planned and resourced development stages (including market launch) with pre-defined, tough "go" or "kill” critical-decision points in the process.

Finally, Jokioinen and Suomala (2006), in their multiple case study-based research proposed four example of successful innovative firms, and by examining in depth each case, identified the following as the main success factors:

i. high leverage for production efficiency;

ii. short pay-back time for customers;

iii. quick installation;

iv. simple product to be used; 
v. effective and innovative utilisation of well-known technology in the developer company;

vi. short pay back time of the NPD process costs;

vii. better quality of the production process and end product.

Most of the studies above mentioned, however, refer to large, well-established companies; conversely, innovation mechanisms and NPD are rarely investigated in companies with little technological endorsement (Moreira, 2005); there is thus limited knowledge as regard NPD processes within small and medium enterprises (SMEs). Only two notable studies by Woodcock et al. (2000) and Freel (2000) may be cited. The Authors of these works identified a number of common elements with large firms and the main constraint that SMEs have to face with, respectively. On the basis of this premise, our paper aims to add value to the current debate on NPD within SMEs.

\section{Research methodology}

The analysis described in this paper is the result of a case study-based research. A "case study" is defined by Yin (2009) as "an empirical inquiry that investigates a contemporary phenomenon within its real-life context; when the boundaries between phenomenon and context are not clearly evident; and in which multiple sources of evidence are used". Case studies are frequently used as field research where an investigator tries to conjecture answers to 'what', 'how' and 'why' questions, by focusing on observing contemporary events (Yin, 2009).

In this paper, a case study was developed with the purpose of answering two primary research questions, namely:

- $\quad$ which are the main steps of a NPD process in the food industry?

- which are the critical factors affecting the success of NPD in that context and in particular in SMEs?

The intended use of case study-based research is thus theory building (Jaspers, 2007), and, in particular, the aim of the study is identifying best practices in NPD for SMEs operating in the food packaging industry. The reasons for selecting this context mainly refer to the fact that process and product innovations of the food industry are usually the result of cross-discipline ideas, involving, for instance, biology, chemistry, technology, engineering, nutrition and law. Furthermore, the benefits of innovations in the food industry often are not evident in the manufacturing stage; hence, there is the need for field studies which clearly highlight such benefits, as well as the critical factors of successful NPD processes in the food industry.

To select the company to be investigated, we first identified a group of SMEs operating in the food manufacturing or machinery fields, and located in Northern Italy. The group of companies was defined including SMEs which concluded at least one successful NPD process during the last year. Such companies were contacted and asked for their willingness to be investigated through a case study; the company analyzed in this paper was finally selected among those which indicated their availability for a field investigation.

Case studies typically involve multiple sources of information (Yin, 2009): in the present study, the sources of information were two questionnaires, which were used as a guideline for as many semi-structured interviews with the company's managers. The first questionnaire consisted of 15 questions, focusing on:

i. general aspects of product innovation practices used in the company;

ii. the NPD process and its management, referring to a recent product innovation made by the company;

iii. innovation protection mechanisms and their role for the company considered.

The questionnaire was emailed to the company's administrator, and answered through a direct interview in January 2010. Results collected from the interview were elaborated and submitted to the company's administrator for his approval. At the same time, from these outcomes, we identified the need for further investigating some specific aspects, such as the technical features of the product developed and some economic figures of the NPD process. These topics were included in a second questionnaire, which was sent to the company's administrator in April 2010, and answered through a second semi-structured interview. Both interviews were held by some academics of the University of Parma (Italy), which were identified between research experts in innovation, supply chain management, industrial plants and food processing. The results obtained from the case studies were finally validated by the company's top management in May 2010.

\section{Case study}

\subsection{The context: innovation in the food packaging industry}

The food industry has been a relatively slow-moving sector for many years, while recently it has focused more on innovations in marketing, distribution, development of new products and new packaging solutions (Siegrist, 2008). In response to changed life styles, in fact, it has become imperative for food companies to explore ways to improve their productivity, in terms of preserving product safety, using sustainable packaging materials, implementing flexible and standardized technology, and adopting proven management principles. In the food industry, innovations are currently driven by the goal to market more healthful foods, as well as by some general innovation trends, such as the creation of food that can 'drive' health, the push for variety, the market growth 
and expansion of the food and beverage industries (Moskowitz and Hartmann, 2008). These trends are forcing the food industry to develop new products, packaging and equipments, in order to satisfy the customer's needs in terms of flexibility and quality. In the context of the food packaging, in particular, the attention has been focused on increasing the ease of use of the package and improving the shelf life and quality of packaged foods (Mahalik and Nambiara, 2010).

A recently developed packaging system is the Form Fill Seal (FFS) technology, that is an integrated system of forming a package, filling the product into the package and sealing it, usually in a single machinery. Such technology provides high production rates at economical and flexible mechanism, and enables realizing a flexible single-dose packaging, made with polymeric materials (Lee et al., 2008). These materials (like Ethylene Vinyl Alcohol, EVOH, or Ethylene Vinyl Acetate, EVA) have almost completely substituted the cellulosic ones, thus allowing the reduction of food aroma losses through the packaging, and increasing the shelf life of food products (Peychès-Bach et al., 2009).

The field of single-dose packaging made with FFS technology, which is the specific context of our study, has shown a considerable increase in innovation and NPD, as confirmed by data on international and Italian patents applications (Table 1). As can be seen from Table 1, the number of food packaging patents has significantly increased from 2004 to 2008, moving from 871 to 1048 international patents and from 13 to 20 Italian patents.

Table 1: Trend of International and Italian food packaging patents (source: http://ep.espacenet.com).

\begin{tabular}{lccccc}
\hline \multicolumn{1}{c}{ Year } & 2004 & 2005 & 2006 & 2007 & 2008 \\
\hline International patents & 871 & 884 & 940 & 880 & 1048 \\
Italian patents & 13 & 12 & 10 & 20 & 20 \\
\hline
\end{tabular}

\subsection{The company}

The company examined in the case study is EasyPack Solutions Srl (hereafter referred to as EasyPack). With respect to the classification of the European Commission (2003), the company is a small enterprise, founded in 1985 in San Giovanni in Persiceto, in Northern Italy. EasyPack started its activity operating as a manufacturer of packaging machinery for the food industry, and especially of Form-Fill-Seal machines; in recent years, the company extended its activity to the production of packaging solutions for food products, manufacturing small 3-side seal or 4-side seal sachets. EasyPack offers to its clients not only a mechanical system but the whole process, including the packaging materials, in order to fill all food products assigned to the single-dose sector.

Besides the food industry, products manufactured are commercialized in the chemical, cosmetic and pharmaceutical markets, both in Italy and abroad. The company uses a network of sales agents located throughout the world, and controls four subsidiaries in Spain, Korea, South Africa and North America.

\subsection{The product analysed}

The product examined in this study is an innovative single-dose packaging, called Easysnap. Easysnap is a single-dose sachet intended to replace the 4-side or 3-side seal packages, which are commonly used when packaging small contents of food fluids (from 2 to $25 \mathrm{ml}$ ). Examples of products packed in 4-side or 3-side seal sachets are mayonnaise and mustard among foods, or shampoo or shower gel among cosmetics.

The innovation in the product developed primarily consists in the functional characteristics of new packaging. The package is, in fact, extremely easy to use, because the opening mechanism allows the sachet to be opened with one hand by the user. The package should be taken by the user with one hand and bent, until a micro-fracture of the plastic material is generated. The subsequent pressure by the user involves an extension of the fracture, as well as the complete breaking and consequent product flow. As a function of the pressure he applies, the user is also able to precisely control the amount of product flowing out, avoiding dirty. As regards the organoleptic properties of the content, the product is packaged in the absence of air, and thus benefits from a long shelf life.

To protect the innovative opening mechanism, Easysnap was recently patented. In fact, the opening mechanism requires accurate evaluation and design of the thickness of the plastic material, which makes it possible to open the package as a result of pressure applied by the user. Easysnap thus differs from technological solutions available on the market in that the package is not "cut", as in many other types of packaging; rather, a cavity is generated, exploiting the elastic properties of the packaging material. This solution has some advantages. First, it allows keeping intact the plastic material, which provides higher protection to the product; moreover, such a solution also avoids non-controlled flow of product.

EasyPack also engineered proper automated machines for the production of the new packaging; such machines were designed in order to manufacture a sachet with internal and external grooves, whose depth depends on the density of the product packed. Specific customer's requirements could also affect the grooves' depth: for example, the customer may require that a viscous product flows out all together, but only when the sachet has been completely opened. The automated packaging machines were also patented. It will be explained in the next section that patents are crucial for new packaging solutions; conversely, the relevance 
of patenting the machine is lower, and does not fully protect the innovation. As a matter of fact, it is always possible that a competitor finds a different technical solution to achieve a similar industrial output (EasyPack itself designed different machines, besides the one patented, that can be used to produce Easysnap). On the other hand, patenting the machine could be a "barrier" for competitors of EasyPack, as it prevents them to build machines that operate with the same procedure as those patented.

\subsection{The steps from "concept" to "patent"}

As mentioned, a typical NPD process starts with the identification of an opportunity in the market and ends with the successful launch of the product on the market. According to the findings obtained from the case study, the NPD process of Easysnap consists of 5 steps (Figure 2), namely:

i. $\quad$ identification of the market need and generation of the "idea" of the product;

ii. development of the technological solution;

iii. pre-testing of the product with selected customers;

iv. innovation protection through Italian patents;

v. innovation protection through international patents.

The production process for Easysnap partially overlaps the NPD process, as it consists of:

i. identification of the market need and generation of the "idea" of the product;

ii. development of the technological solution;

iii. pre-testing of the product with selected customers;

iv. product manufacturing and launch in the food packaging market;

v. expansion in different markets.

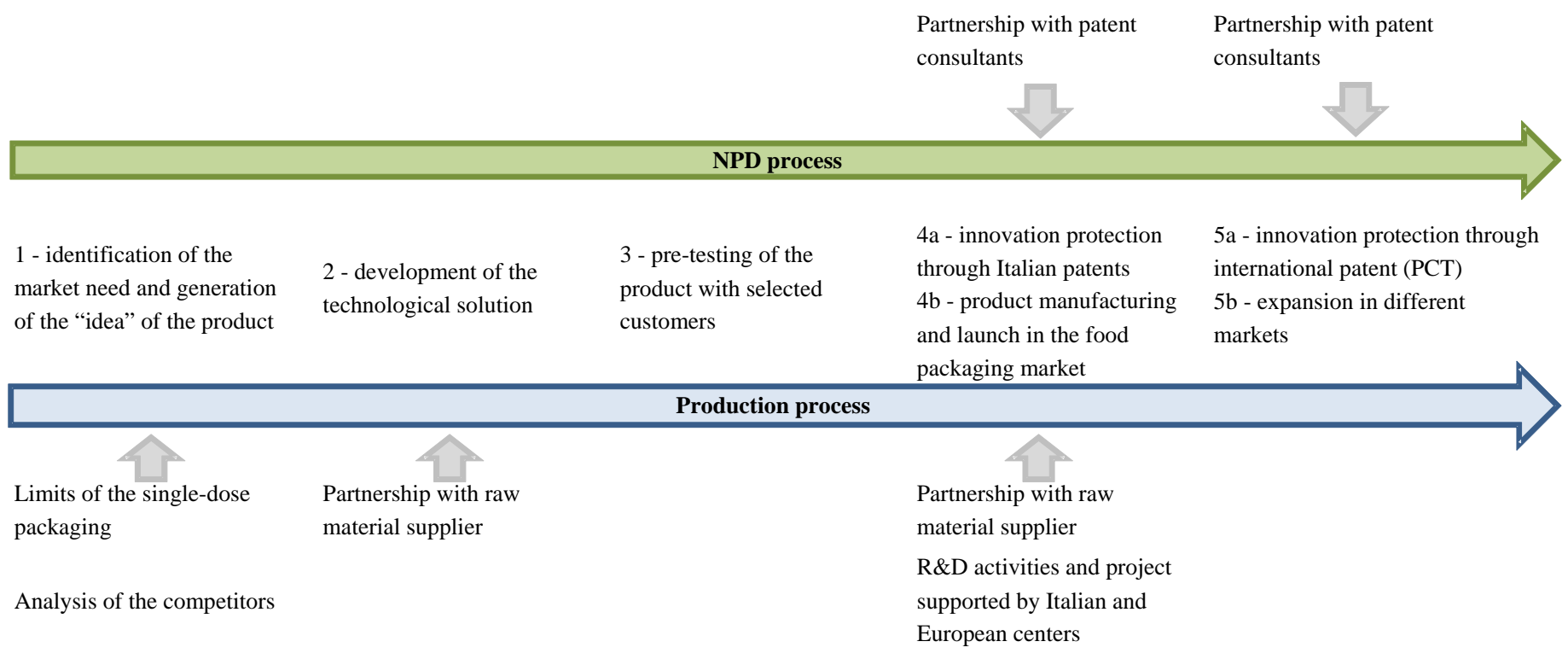

Figure 2. New product development process and production process of Easysnap.

The starting point for the NPD process was the generation of the "idea" of the product (step 1). As mentioned, EasyPack started its activity as a manufacturer of automatic packaging machines, for 4-side or 3-side seal packages, and, in this context, the company achieved a good market share and was able to expand its production in foreign markets (e.g., China). On the basis of the success gained in the packaging machinery industry, the company decided to enter the product packaging market, where it faced numerous competitors. The idea of the new product was generated starting from the analysis of the packaging systems manufactured by competitors, as well as from the investigation of the main limits of single-dose sachets, both 4-side or 3-side seal, commonly used for packaging food and pharmaceutical products. Hence, the idea of the new product has not been a real "intuition"; rather, it was generated as a result of marketing research of the company, as well as of the analysis of different packaging solutions currently available for food products. The main limit the company found for single-dose sachets was the need for the user to use both hands when opening the package. Of course there is the need for breaking the sachet, to open it; nonetheless, the company developed the idea of a single-dose sachet that could be opened using only one hand, by means of a natural hand movement.

Once the idea was generated, the company started the development of the technological solution to engineer it (step 2). More precisely, the company originally pondered several possible solutions. For instance, one possible technological solution was 
grounded on the application of a supplementary element inside the sachet, which could be used to break the packaging though the hand movement. This solution was not engineered, however, due to the fact that adding a supplementary element would have increased the cost of the packaging machines, and the complexity of the packaging process as well. After a preliminary screening, several technical solutions were dropped, due to either technical limitations, difficulties in industrializing them or limited economical profits. The company finally decided to focus its attention on the development of a technical solution based on a special kind of plastic film, whose structure allowed the internal and external breaking of the sachet, thanks to the hand movement by the user. To engineer such solution, the company developed a partnership with a supplier, operating as a plastic manufacturer, which was directly involved in the NPD process. The partnership allowed EasyPack to benefit from the considerable know-how of the supplier in the field of plastic materials, as well as to save significant money (about 50\%) in the purchase of raw materials for manufacturing activities. At the same time, the partnership with the supplier also had some shortcomings. For instance, the chosen partner is a big company, with limited flexibility: as a matter of fact, the supplier required quite long time (approx 6 months) to fulfill an order received from EasyPack. Obviously, the limited flexibility of the supplier in turn affects the capability of EasyPack to provide the final customers with the product in a relatively short time.

After the engineering of the technological solution, the product underwent a pre-testing with selected customers, by which it was proposed to some customers at Italian and European trade fairs (step 3). At this stage, the product proposed was still in a prototypical form: for instance, the plastic material used was different from that currently adopted, and, as a consequence, the manufacturing process could not be fully automated. This also resulted in scarce precision when opening the single-dose sachet, and to unexpected breaking as well. Despite the limits of the prototype, the pre-testing phase played a crucial role for the company to collect the voice of the customer as regards to the new product, as well as to identify the need for modifications to be made to the product in response to further customer's needs. At the same time, pre-testing also allowed the company to start the presentation of the new product to potential customers. On the basis of the interest raised by the new product, the company proposed it to additional customers. To enhance the attractiveness of the product, the company paid particular attention to differentiate it from the products offered by competitors. Specifically, the company undertook considerable efforts in research and development (R\&D), to obtain an innovative plastic material which could preserve the product for 24 months instead of 12 months, thus providing unique and tangible customer's benefits. Due to the strategic role of raw materials in achieving this aim, R\&D activities were still supported by the partnership with the supplier of plastic materials. Moreover, specific R\&D activities and projects (aimed, for instance, to assess the preservation and the organoleptic properties of the product packaged) were carried out thanks to the collaboration with research centers, such as Italian universities and foreign research centers.

As regards to the NPD process, before starting the launch of the new product, the company submitted an application for an Italian patent, covering the technical features of the new product (step 4a). The aim of the patent was to protect the intellectual property of the innovative solution, and, in particular, the opening mechanism of the sachet. Moreover, the Italian patent was required before starting the large-scale production of the new product: in fact, in the food packaging industry, protecting the technological solution is crucial, since the significant cost for engineering it and manufacturing the new product can be paid back only through exclusive use of the technological innovation. In this phase, as well as during the application for the international patent, the company was supported by patent consultants. At the time EasyPack applied for the Italian patent (late 2006), there was no need for the Italian patent office to check the technical contents of the patent. That is, the contents of a new patent application were assumed as valid and innovative, until otherwise proven, meaning that any other company could prove the inadequacy of the patent contents within 24 months from the submission. The underlying rational for this procedure is that, before applying for a patent, a company should personally check the national patents databases, to ensure that the solution developed is really innovative ${ }^{1}$. The guidance of patent consultants was fundamental for EasyPack to ensure that such checks are accurate and extensive.

As mentioned, in the context of food packaging, the Italian patent is often a prerequisite to start the large-scale production of the new product and its launch on the market. It should also be noted that, for the company examined, the application for the Italian patent did not delayed the launch of the product on the market, as the patent application was submitted before starting the largescale manufacturing of the product. Overall, the time to market of Easysnap (i.e., the time elapsed from the generation of the "idea" of the new product and the first placement on the market) was about 18 months, which is a relatively short time compared to the typical time to market of a new product. This leads to obvious advantages for the company, as the reduction of NPD time creates opportunities for gaining market share, increasing profits, and ensuring long-term competitiveness (Ittner and Larcker, 1997; Griffin, 1997). At the same time, the choice to start the large-scale production of the new product as soon as the application for the Italian patent was submitted entails obvious risks. In fact, it is clear that the submission for a patent does not ensure the success of the application: due to the lack of checks on the technical contents of the patent at the time an application is submitted, any competitor could prove the inadequacy of the patent pending, nullifying the economical investments made by a company.

The international patent application was submitted by EasyPack to extend the intellectual property of the technological solution at international level (step 5a). The international patent chosen by EasyPack is the Patent Cooperation Treaty (PCT). Submitting an

\footnotetext{
${ }^{1}$ It has to be mentioned that the procedure described has changed in late 2008. In particular, the Italian patent office now needs to check the innovative contents of any patent, as well as the contents of similar previous patents, before accepting any application for an Italian patent (Ufficio Italiano Brevetti e Marchi, 2008).
} 
application for a PCT patent involves significant costs, as it requires a detailed examination of the technical contents of the patent, to ensure its innovation; moreover, the analysis should be extended to all countries where the PCT should be recognized as valid. At the time of writing, PCT embraces a total of 142 countries (World Intellectual Property Organization, 2006). This is why the company submitted the PCT application two years after the Italian patent (late 2008). After the international application, EasyPack could start manufacturing and selling the new product in foreign countries, generating considerable revenues from sales and covering part of the costs incurred for the development of Easysnap. Finally, in 2009, the company has applied for worldwide patent.

As mentioned, in parallel with the Italian patent application, the company started product manufacturing and launch in the Italian food packaging market (step 4b). It is well known that adequately planning the launch on the market is a relevant point to ensure the success of the new product (Ionescu and Stancu, 2007). In the case in exam, the launch phase of Easysnap was supported by the recruitment of several new staff units, which acted as project managers in carrying out and monitoring the launch of the product on the market. More precisely, the company embodied a chemical engineer, some lawyers and an industrial engineer in its staff. The chemical engineer was a past employee of the supplier of plastic material, partner of EasyPack, and operated in the R\&D function; currently, he is in charge for the procurement of plastic materials, meaning that he still has close relationships with the partner of EasyPack. The lawyers were embodied in the company's staff with the purpose of taking care of bureaucracy associated with patents and certifications related to new products. Finally, the industrial engineer was included in the staff of EasyPack with the purpose of supervising the start-up of a company's subsidiary, in Spain, and the bureaucracy associated.

The last step of the production process of Easysnap was the expansion in different markets (step 5b). This phase was supported by a strategic partnership with a company operating in the pharmaceutical sector; the partnership allowed EasyPack to enter this market field, as well as similar contexts (e.g., health, beauty care and cosmetics sectors). To enter such markets, the company started by manufacturing products for third parties, with a limited annual production. Currently, the Italian production plant of the company manufactures between 8 and 9 million single-dose sachets per year, which are sold in the food market. For the same market, about 10 million sachets per year are manufactured in the production plant in South Africa. The market penetration of EasyPack in the cosmetics, health care and pharmaceutical fields is lower, due to the more recent entry into those markets.

\subsection{Economic analysis}

Recouping the investments in NPD is crucial for ensuring company's competitiveness and generating future revenue from the new products. For this reason, we have conducted an economic analysis of the NPD process of Easysnap, following the main phases of the process, as described in the section above. The analysis is based on a 4-year horizon, which approximately covers the years from 2006 to 2009. For each year, we propose a percentage sharing of the investments required in the different steps of the NPD process, as shown in Figure 3.

For confidentiality reasons, we are not allowed to provide the detailed economic figures, such as investments, costs and revenues, of the company investigated; hence, all economic figures are expressed as percentage values with respect to the company turnover of each year. The economical analysis in Figure 3 shows that the steps 1-3 of the NPD process absorb most of the company's turnover during the first year; this indicates that the initial activities of the NPD requires significant financial efforts. Similarly, the development of the technological solution (step 2) still requires relevant investments during year 2.

Conversely, during the last years, innovation protection mechanisms become the activities which require the most significant efforts. This confirms the relevance of innovation protection for the context examined and for the technological solution developed. Finally, from the total cost shown in Figure 3, it can be deduced that the NPD did not generate revenues during years 12. In fact, the cost of the NPD process covers the overall amount of the annual turnover of the company, meaning that the turnover is entirely reinvested. Conversely, in years 3-4, the total cost of the NPD process is lower than $100 \%$ (approx $80 \%$ during year 3 and $50 \%$ during year 4), indicating that the turnover of the company has significantly increased. Eventually, this suggests that the NPD process started generating positive revenues from year 3 onwards. 


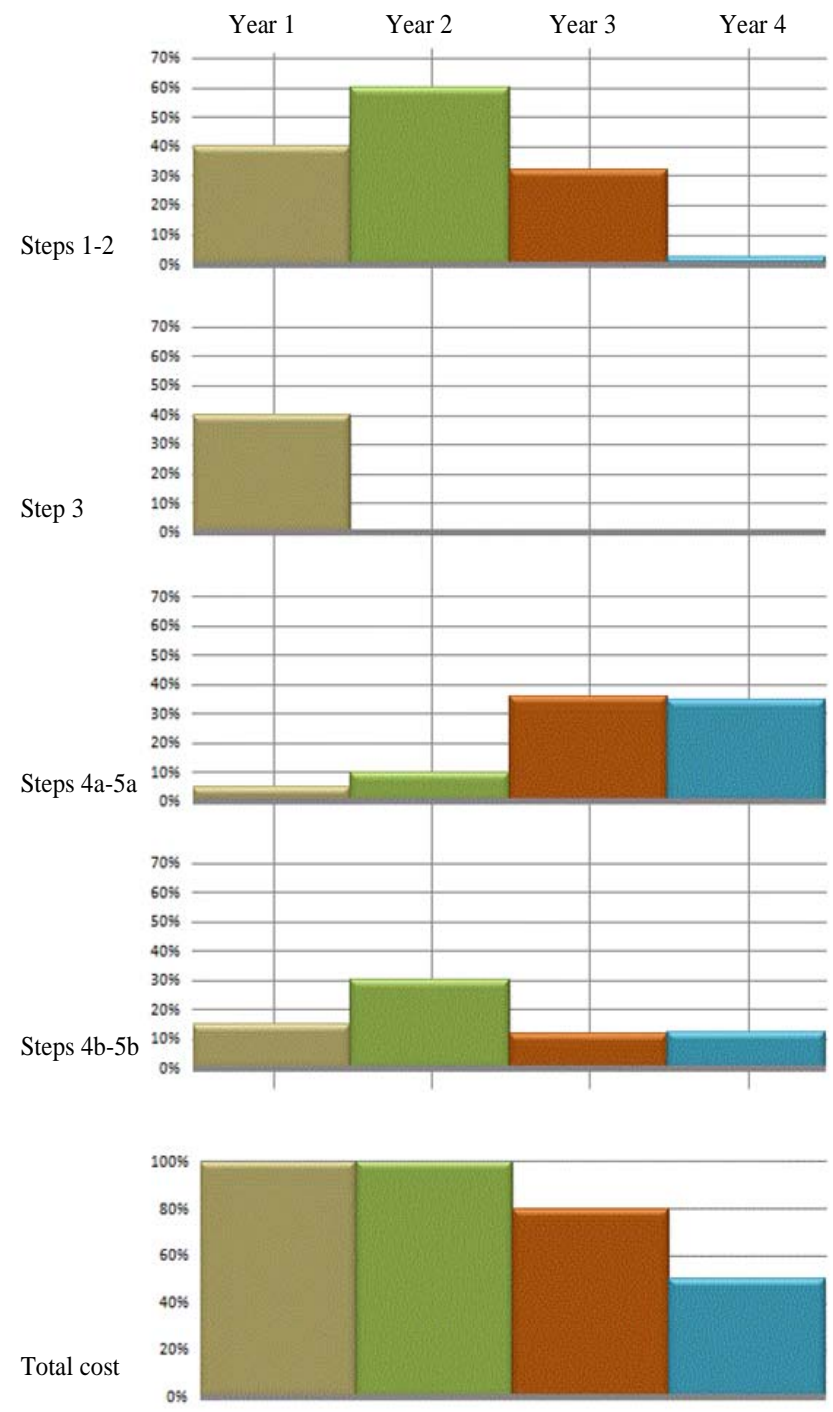

Figure 3. Economic analysis for the new product development process.

\section{Conclusions}

Responsive and timely NPD has become even more critical in the today's highly competitive global environment. The need to respond quickly to these dynamic forces requires every company to integrate rapidly the perspectives and needs of product developers as well as of the customer. As for the food industry, such context has seen significant advances in the packaging sector, with the development of active and intelligent innovations. These advances have led to improved food quality and safety. While some innovations have stemmed from unexpected sources, most have been driven by changing consumer preferences or specific customer's requirements.

The issue discussed in this article was the NPD process and those factors that determine its success within a food packaging SMEs, where still little attention has been paid to this matter. In particular, we have attempted to provide a framework for the NPD process, grounding on the literature on the traditional NPD process and on the analysis of a real-life experience. Specifically, with this purpose in mind, the paper has explored a successful industrial NPD case, in order to present the lessons from the real scenario. First, the paper has illustrated the variety of interpretations that the concept of NPD, and of NPD success in particular, receives. Second, by exploring the case history, the paper has drawn a picture of the 5-step NPD process, as well as it identifies the background successful factors present in the case.

From the analysis of the case study, it can be argued that the success of the NPD process of the company examined was grounded on some main strong points, shown in Figure 3 and described below.

i. Differentiation. The company has paid particular attention to increase the attractiveness of the new product in comparison with the product manufactured by the competitors. The generation of the idea, in particular, was focused on the analysis of the competitors, to identify the limits of their products and propose an innovative solution. Similarly, extensive R\&D 
activities were accomplished by the company during the pre-testing of the product, to develop a plastic material which could improve the preservation of the package contents for 24 months. By means of these activities, the company was able to deliver the customers unique and tangible benefits, increasing the perceived value of the product;

ii. Voice of the customer. The pre-testing was the phase which allowed the company to collect the opinions of the customers as regard to the new product, as well as to improve its technical characteristics in response to customer's needs;

iii. Market launch. The launch of the new product was accurately planned by the company, and several resources were spent in this phase. Specifically, the company has coupled the launch of the new product with innovation protection mechanisms, to protect the product innovation; moreover, the launch of the new product was supported by a crossfunction team, involving four new staff units. The team members acted as project managers in promoting the new product and monitoring its launch on the market;

iv. Innovation protection mechanisms. The company examined has chosen to protect the product innovation with both national and international patents. Innovation protection is not always included in a typical NPD process. In fact, innovation protection, particularly at international level, often involves significant cost, which could prevent a company to undertake this step. Instead, in the case in exam, the significant efforts of the company toward innovation protection have been crucial for the successful launch of the new product on the market;

v. Reduced time to market. A short time to market is particularly relevant in the food context (and especially in the food packaging industry), as the food market increasingly requires new products and new packaging solutions. In the case examined, the company was able to limit the overall time to market of the new product to about 18 months, which is relatively short compared with typical NPD processes. This involved significant benefits for the company, such as opportunities for gaining market share, increased profits, and long-term market competitiveness.

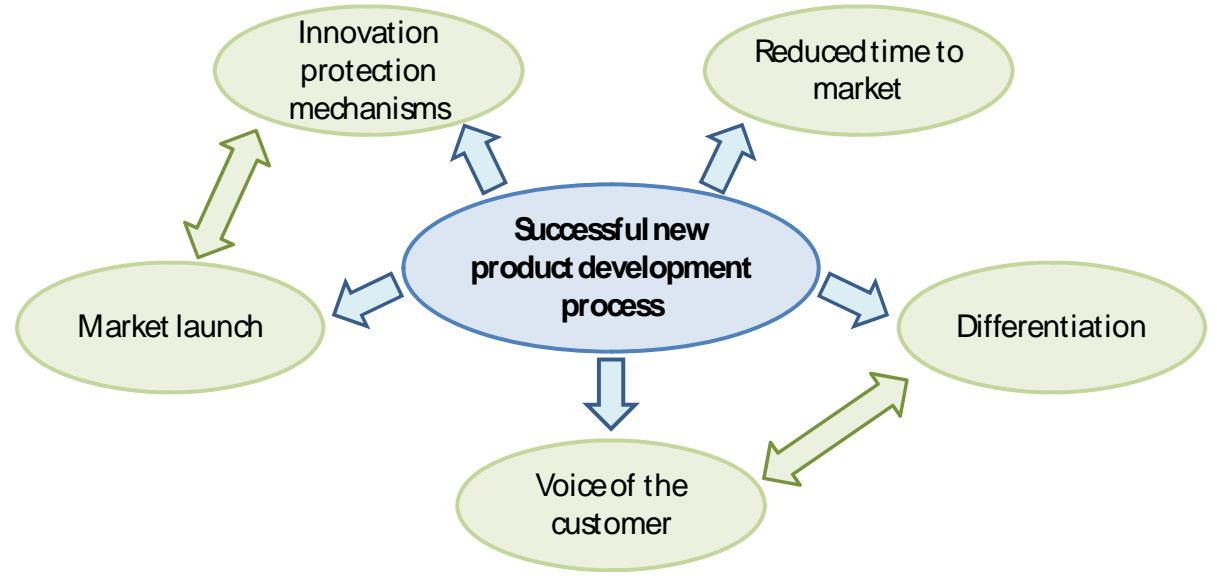

Figure 3. Critical success factors of new product development for the case study.

The above factors provide useful guidelines and indications for a successful NPD process in the food industry. We thus believe that investigating innovation mechanisms in the food context can provide interesting insights for practitioners in other different fields.

At the same time, we acknowledge that our results cannot be generalised to other contexts: our study, in fact, is focalized on a specific industry, while different sectors might have a different approach to the NPD process and patenting activities. These limitations will be carefully considered and will hopefully inform future research. Moreover, as we have examined a case study referring to a SME, the NPD process we defined could not be suitable for application, for instance, in a big company. Hence, the logical prosecution of this work is to define a more general model for NPD processes in the context of the food industry. This could be done, for instance, by multiple case studies and cross-analyses between them.

\section{References}

Abraham, B.P. and Moitra, S.D. 2001. Innovation assessment through patent analysis, Technovation, Vol. 21, pp. 245-252.

Baker W.E. and Sinkula J.M. 1999. The synergistic effect of market orientation and learning orientation on organizational performance, Journal of Academy of Marketing Science, Vol. 27, No. 4, pp. 411-427.

Balkin D.B., Markaman G.D. and Gòmez-Mejìa L.R. 2000. Is CEO pay in high-technology firms related to innovation?, Academy of Management Journal, Vol. 43, No. 6, pp. 1118-1129.

Calantone R.J., Vickery S.K. and Droge C. 1995. Business performance and strategic new product development activities: an empirical investigation, Journal of Product Innovation Management, Vol. 12, pp. 214-223. 
Clarysse B., Van Dierdonck R., Gabriels W., Lambrechts J. and Uytterhaegen M. 1998. Strategische verschillen tussen innovative KMOs: een kijkje in de zwarte doos. Publication No. 5, IWT, Brussels.

Cooper R.G. 1999. The invisible success factors in product innovation, Journal of Product Innovation Management, Vol. 16, pp. 115-133.

Cooper R.G. 2001. Winning at new product: accelerating the process from idea to launch. New York, Perseus Publishing.

Damanpour F. and Gopalakrishnan S. 2001. The Dynamics of the Adoption of Product and Process Innovations in Organizations, Journal of Management Studies, Vol. 38, No. 1, pp. 45-65.

Darroch J. and McNaugton R. 2002. Examining the link between knowledge management practices and types of innovation, Journal of Intellectual Capital, Vol. 3, No. 3, pp. 210-222.

Drucker P. 1985. Innovation and Entrepreneurship, Harper \& Row, New York, NY.

European Commission 2003. Commission Recommendation 2003/361/EC of 6 May 2003 concerning the definition of micro, small and medium-sized enterprises. Official Journal L124 of 20.05.2003

Garcia R. and Calantone R. 2002. A critical look at technological innovation typology and innovativeness terminology: a literature review, The Journal of Product Innovation Management, Vol. 19, pp. 110-132.

Hanan M. 1970. Effective coordination of marketing with research and development, Handbook of modern marketing, Victor Buell (ed.), McGraw-Hill.

Ionescu F.T. and Stancu A. 2007. Key success factors in new product development process. The Journal of the Faculty of Economics - Economic Science Series, Vol. 1, pp. 984-986

IRI 2000. R\&D facts 2000, Industrial Research Institute, Washington, DC.

Jaspers F. 2007. Case study research: some other applications besides theory building. Journal of Purchasing \& Supply Management, Vol. 13, pp. 210-212.

Jimenez J., Valle R.S. and Espallardo M.H. 2008. Fostering innovation. The role of market orientation and organizational learning, European Journal of innovation management, Vol. 11 No. 3, pp. 389-412.

Jokioinen I. and Suomala P. 2006. Lessons learned from industrial success stories, European Journal of Innovation Management, Vol. 9, No. 4, pp. 370-395.

Klompmaker J.E., Hughes G. and Haley R. 1976. Test marketing in new product development, Harvard Business Review, Vol. 54, pp.128-38.

Lee D.S., Yam, K.L., Piergiovanni, L. 2008. Food Packaging Science and Technology. Boca Raton (USA): CRC Press Taylor\&Francis

Lundvall B.A. 1992. National Systems of Innovation: towards a theory of innovation and interactive learning, Frances Printer, London.

Lyon D. and Ferrier W. 2002. Enhancing performance with product-market innovation: the influence of the top management team, Journal of Managerial Issues, Vol. 14, No. 14, pp. 452-469.

Mahalik N.P. and Nambiara A.N. 2010. Trends in food packaging and manufacturing systems and technology, Trends in Food Science \& Technology, Vol. 21, No. 3, pp. 117-128.

McGuire E.P. 1973. Evaluating new product proposals, The conference board report, No. 604.

Millward H. And Lewis A. 2005. Barriers to successful new product development within small manufacturing companies, Journal of Small Business and Enterprise Development, Vol. 12, No. 3, pp. 379-394.

Montoya-Weiss M.M. and Calantone R.J. 1994. Determinants of new product performance: a review and meta-analysis, Journal of Product Innovation Management, Vol. 11, pp. 397-417.

Moreira A.C. 2005. Supplier-buyer collaboration in new product development: four case studies involving SMEs. Brazilian Journal of Operations \& Production Management, Vol. 2, No. 1, pp. 5-24.

Moskowitz H. and Hartmann J. 2008.Consumer research: creating a solid base for innovative strategies. Trends in Food Science \& Technology, Vol. 19, No. 11, pp 581-589.

Peychès-Bach A., Moutounet M., Peyron S. and Chalier P. 2009. Factors determining the transport coefficients of aroma compounds through polyethylene films. Journal of Food Engineering, Vol. 95, No. 1, pp. 45-53.

Rothwell R., Freeman C., Jervis P., Robertson A. and Townsend J. 1974. Sappho updated-Project SAPPHO Phase 2, Research Policy, Vol. 3, pp. 258-291.

Scarborough N. and Zimmerer T. 2002. Essentials of Entrepreneurship and Small Business Management, Paperback.

Shenhar A.J., Tishler A., Dvir D., Lipovetsky S. and Lechter T. 2002. Refining the search for project success factors: a multivariate, typological approach, $R \& D$ Management, Vol. 32, No. 2, pp. 111-26.

Sheperd C. and Ahmed P.K. 2000. From product innovation to solutions innovation: a new paradigm for competitive advantage, European Journal of Innovation Management, Vol. 3, No. 2, pp. 100-106.

Siegrist M. 2008. Factors influencing public acceptance of innovative food technologies and products. Trends in Food Science \& Technology, Vol. 19, No. 11, pp 603-608.

Thomas, V.J., Sharma, S. and Jain, S.K. 2010. Using patents and publications to assess R\&D efficiency in the states of the USA, World Patent Information, forthcoming. 
Tidd J., Bessant J. and Pavit K. 1997. Managing Innovation: Integrating technological, market and organizational change, John Wiley \& Sons Ltd, Chichester.

Ufficio Italiano Brevetti e Marchi, 2008. Istruzioni deposito domanda brevetto nazionale. Available at http://www.uibm.gov.it/it/Incontro\%20Brevetti-PI-5.pdf (accessed June 2010).

Wheelwright S.C. and Clark K.M. 1992. Revolutionary product development, The Free Press, New York, NY.

World Intellectual Property Organization 2006. Protecting your inventions abroad: frequently asked questions about the Patent

Cooperation Treaty (PCT). Available at http://www.wipo.int/export/sites/www/pct/en/basic_facts/faqs_about_the_pct.pdf

(accessed June 2010).

Yin, R.K. 2009. Case Study Research: Design and Methods. Fourth Edition. SAGE Publications. California.

\section{Biographical notes}

Dr. Barbara Bigliardi graduated (with distinction) in 2004 in Industrial Engineering and Management at the University of Parma and holds a Ph.D. in Industrial Engineering from the same University in 2008, with a thesis on the technological innovation management in the food machinery industry. Since 2005 she has been researcher at the Department of Industrial Engineering of the same University.

She is currently teaching "Business administration" at the degree courses in Industrial Engineering and Management and Mechanical Engineering, and "Economics and Corporate Organizations A" at the degree courses in Information Engineering (Computer Engineering, Electronic Engineering, and Communication Engineering) at University of Parma. She is also strongly involved in Executive Education running seminars for public and private organisations. Her primary research interests focus on innovation, human resources management, performance management systems, knowledge asset \& intellectual capital management and entrepreneurship. She has authored or co-authored many publications, including articles and research reports on the range of research topics listed above. Her research has been published on international journal, as well as on national and international conferences. She is also referee for international scientific journals.

Dr. Eleonora Bottani graduated (with distinction) in 2002 in Industrial Engineering and Management at the University of Parma (Italy), where she is lecturer (with tenure) in Mechanical Industrial Plants since 2005. In March 2006, she got her Ph.D. in Industrial Engineering at the same University. She taught "Supply Chain Management" to the Industrial Engineering and Management class, and, at present, she teaches "Logistics for the Food Industry" to the Mechanical Engineering for the Food Industry class. Her research activities concern logistics and supply chain management issues, and encompass intermodal transportation, development of methodologies for supplier selection, analysis and optimization of supply chains, supply chain agility, supply chain modeling and performance analysis. As secondary research topics, she studies industrial plants, with a particular attention to process optimization and plant safety. Recently, she started studying the use of RFID technology as a tool for the optimization of logistics processes and supply chain dynamics. Results of her studies related to the above topics have been published in about 60 scientific papers, most of which appear in national and international journals, as well as in national and international conferences. She acts as a referee for about 40 international scientific journals and for several international conferences. She is editorial board member of two international scientific journals.

Prof. Roberto Montanari graduated (with distinction) in 1999 in Mechanical Engineering at the University of Parma (Italy), where he is employed as Associate Professor since 2005, teaching "Industrial Plants" to the Industrial Engineering and Management class. From 2001 to 2005, he worked as a lecturer at the Faculty of Agriculture of the same University, where he taught "Food processing plants" and "Machines and Equipments of the Food industry" to the Food Science class. In 2003, he was visiting professor at the New Jersey Institute of Technology (USA) where he spent 7 months for research purpose. His research activities concern equipment maintenance, power plants, food plants, logistics, supply chain management, supply chain modeling and simulation, inventory management. He has published his research in several qualified international journals, as well as in national and international conferences. He acts as a referee for numerous scientific journals such as European Journal of Operational Research; International Journal of Systems Science; Computers \& Industrial Engineering; Chemical Product and Process Modeling; International Journal of Food Science and Technology; and International Journal of Quality and Reliability Management. He is editorial board member of two international scientific journals.

Dr. Giuseppe Vignali graduated in 2004 in Mechanical Engineering at the University of Parma. In 2009, he held a PhD in Industrial Engineering at the same university, related to the analysis and optimisation of food processes. Since August 2007, he works as a Lecturer at the Department of Industrial Engineering of the University of Parma, and, since the employment at the University, he has been teaching "Materials, Technologies and Equipments for Food Packaging” to the Food Industry Engineering class. His research activities concern food processing and packaging issues and safety/security of industrial plant. Results of his studies related to the above topics have been published in more than 20 scientific papers, some of which appear both in national and international journals (e.g., Safety Science, Chemical product and process modelling, Prevention today, Food Manufacturing Efficiency), as well in national and international conferences. He acts also as a referee for an International Journal: Prevention Today.

Received June 2010

Accepted November 2010

Final acceptance in revised form November 2010 